\title{
A Reduced Graphene Oxide/Gold Nanoparticles Composite Modified Glassy Carbon Electrode as Electrochemical Sensor for Calcium Ions Detection in Bottled Water
}

\author{
Nawal A. Alarfaj ${ }^{1}$, Maha F. El-Tohamy ${ }^{1} \dagger^{*}$, Hesham F.Oraby ${ }^{2}$ \\ ${ }^{1}$ Department of Chemistry, College of Science, King Saud University, P.O. Box 22452, Riyadh 11495, \\ Saudi Arabia \\ $†$ Parmanent address: General Administration and Medical Affairs, Zagazig University, Egypt \\ ${ }^{2}$ Deanship of Scientific Research, Umm Al-Qura University, Makkah, Saudi Arabia \\ *E-mail: moraby@ksu.edu.sa or star2000star@gmail.com
}

doi: $10.20964 / 2020.06 .49$

Received: 4 February 2020 / Accepted: 17 March 2020 / Published: 10 May 2020

\begin{abstract}
The present study suggested an ultrasensitive reduced graphene oxide (rGO)/gold nanoparticles (AuNPs) modified electrochemical sensor for the detection of trace $\mathrm{Ca}^{2+}$ ions in bottled water. The detection was performed by the aid of calcium ligand complexing agent ethylenediaminetetraacetic acid (EDTA). The presence of rGO as a large surface area and supporting material to AuNPs provides a facile electrochemical reduction of $\mathrm{Ca}^{2+}$-EDTA in the presence of ammonia buffer of $\mathrm{pH}=10$. Under optimized experimental conditions, the fabricated sensor displayed excellent linearity over a concentration range of $2-100 \mu \mathrm{gmL}^{-1}(\mathrm{r}=0.999)$ with calculated detection and quantification limits of 0.01 and $2 \mu \mathrm{g} \mathrm{mL}^{-1}$ for $\mathrm{Ca}^{2+}$, respectively. The fabricated modified sensor was unaffected by the presence of certain possible common interfering species. Using ICH guidelines the proposed method was validated with respect to various analytical parameters including, linearity, detection and quantification limits, precision, accuracy, etc. Moreover, a comparative analytical study for calcium detection using the proposed electrochemical method and other analytical methods was carried out. It revealed good reproducibility, repeatability and success in the detection of trace $\mathrm{Ca}^{2+}$ ions in different brands of bottled water.
\end{abstract}

Keywords: Graphene oxide nanoparticles; Gold nanoparticles; Bottled water, Modified sensor; $\mathrm{Ca}^{2+}$.

\section{$\underline{\text { FULL TEXT }}$}

(C) 2020 The Authors. Published by ESG (www.electrochemsci.org). This article is an open access article distributed under the terms and conditions of the Creative Commons Attribution license (http://creativecommons.org/licenses/by/4.0/). 